\title{
Infants' behavioral and physiological profile and mother-infant interaction
}

\author{
Raquel Costa' and Barbara Figueiredo'
}

\begin{abstract}
This study aims to (a) identify and profile groups of infants according to their behavioral and physiological characteristics, considering their neurobehavioral organization, social withdrawal behavior, and endocrine reactivity to stress, and to (b) analyze group differences in the quality of mother-infant interaction. Ninety-seven 8-week-old infants were examined using the Neonatal Behavioral Assessment Scale and the Alarm Distress Baby Scale. Cortisol levels were measured both before and after routine inoculation between 8 and I 2 weeks. At I 2 to 16 weeks mother-infant interaction was assessed using the Global Rating Scales of Mother-Infant Interaction. Three groups of infants were identified: (a) "withdrawn"; (b) "extroverted"; (c) "underaroused." Differences between them were found regarding both infant and mother behaviors in the interaction and the overall quality of mother-infant interaction. The identification of behavioral and physiological profiles in infants is an important step in the study of developmental pathways.
\end{abstract}

\section{Keywords}

behavior, cortisol, endocrine reactivity, infant, mother-infant interaction, neurobehavioral organization, physiology, social withdrawal, stress

In the first 3 months of life, mother and infant establish patterns of reciprocal interaction (Crockenberg \& Smith, 2002). Since both infant and mother act on each other mutually and reciprocally, the characteristics of both might contribute to the quality of the dyadic interaction (Slentz \& Krogh, 2001). The fact that the infants' behavior attracts adults to interact with him/her suggests that this might be a powerful predictor of his/her potential for future development, since this factor is likely to shape the environment to react in an appropriate and individualized way.

Although mother-infant interaction has been the focus of numerous studies, most of the research in this field analyses the impact of maternal circumstances, such as prenatal and postnatal psychopathology, on mother-infant interaction (e.g., Field, Diego, Hernandez-Reif, \& Ascencio, 2009; Hornstein et al., 2006), and few have considered infants' contribution in this process. The infant is not passive in the interaction with the environment, and so his/her individual characteristics can elicit specific behaviors from the caregiver (Bell, 1968). Studies on the influence of an infant's characteristics at birth on patterns of mother-infant interaction are therefore relevant and have relied mainly on infant emotionality (e.g., van den Boom \& Hoeksma, 1994), neonatal neurobehavior (e.g., Nugent et al., 1993), infant social withdrawal (e.g., Puura, Guedeney, Mantymaa, \& Tamminen, 2007), and endocrine reactivity and recovery (e.g., Albers, Riksen-Walraven, Sweep, \& de Weerth, 2008; Azar, Paquette, Zoccolillo, Baltzer, \& Tremblay, 2007; Kaplan, Evans, \& Monk, 2008; Kerbel, Mertesacker, \& Pauli-Pott, 2004; Spangler, Schieche, Ilg, Maier, \& Ackerman, 1994).

Past research has pointed out the association between specific aspects of infants' characteristics and the quality of mother-infant interaction. This study intends to provide evidence regarding a more global and broad perspective of the infant, considering the interplay of physiological and behavioral features and its association with the quality of mother-infant interaction. In the past two decades, child development has become an area of research in several disciplines that include genetic, biologic, environmental, and psychological factors, and the study of the interplay between physiological and psychological processes has increased in the past years (Cernic \& Pennington, 1987; Locke et al., 1985). Still, there is lack of research considering simultaneously behavioral and physiological aspects of infant functioning and their association to the quality of mother-infant interaction.

In this study three features of the infant that have previously been independently related to several developmental disorders, such as attachment disorders, depression, social anxiety, or social problems, were considered: neurobehavioral organization (Horowitz \& Linn, 1984), social withdrawal behavior (Dawson et al., 1999; Guedeney, 1997, 2007; Guedeney, Foucault, Bougen, Larroque, \& Mentré, 2008; Milne, Greenway, Guedeney, \& Larroque, 2009), and endocrine reactivity to acute stress (Ashman, Dawson, Panagiotides, Yamada, \& Wilkinson, 2002; Granger, Weisz, \& Kauneckis, 1994; Lopez-Duran, Kovacs, \& George, 2009; Lundqvist-Persson, 2001; Pérez-Edgar, Schmidt, Henderson, Schulkin, \& Fox, 2008; Sostek \& Anders, 1977).

Not only the infant characteristics, but also the quality of mother-infant interaction is associated with mental, psychomotor, and emotional development as well as with attachment organization and depression (e.g., Cohn \& Tronick, 1983; Evans \& Porter, 2009; Murray \& Cooper, 1997). Maternal responsiveness to the infant predicts infant social, emotional, and cognitive competencies

\footnotetext{
I University of Minho, Portugal

\section{Corresponding author:}

Raquel Costa, School of Psychology, University of Minho, Campus de Gualtar, 47l0-057 Braga, Portugal.

Email: rcosta@psi.uminho.pt
} 
Table I. Sociodemographic and medical data

\begin{tabular}{|c|c|c|c|c|c|}
\hline \multicolumn{2}{|c|}{ Maternal and gestational data } & \multirow{2}{*}{$\begin{array}{l}(\%) \\
96.0\end{array}$} & \multicolumn{2}{|l|}{ Neonatal data } & \multirow{2}{*}{$\begin{array}{r}(\%) \\
7.2\end{array}$} \\
\hline Maternal age & $\geq 20 \Lambda \leq 34$ & & Time of gestation & $<37$ & \\
\hline & $>35$ & 4.0 & & $\begin{array}{l}\geq 37 \Lambda \leq 40 \\
>40\end{array}$ & $\begin{array}{l}82.1 \\
10.7\end{array}$ \\
\hline \multirow[t]{2}{*}{ Years of education } & $<9$ & 3.0 & Gender & Female & 46.9 \\
\hline & $\geq 9$ & 97.0 & & Male & 53.1 \\
\hline \multirow[t]{2}{*}{ Marital status } & Married & 81.0 & Reanimation at birth & No & 94.6 \\
\hline & Cohabiting & 19.0 & & Yes & 5.4 \\
\hline \multirow[t]{2}{*}{ Parity } & Primiparous & 84.2 & Weight & $<2,500 \mathrm{gr}$ & 1.7 \\
\hline & Multiparous & 15.8 & & $\geq 2,500 \mathrm{gr}$ & 98.3 \\
\hline \multirow[t]{2}{*}{ Type of gestation } & Normal & 80.4 & Ponderal index & $<2.5$ & 13.5 \\
\hline & Risk & 19.6 & & $\geq 2.5$ & 86.5 \\
\hline \multirow[t]{2}{*}{ Type of delivery } & Vaginal & 34.2 & Apgar index: Ist min & $<7$ & 3.8 \\
\hline & Vacuum/forceps/Cesarean & 65.8 & & $\geq 7$ & 96.2 \\
\hline \multirow[t]{3}{*}{ Type of anesthesia } & None & 2.6 & Type of feeding & Breast-feeding & 89.4 \\
\hline & Epidural & 86.8 & & Bottle-feeding & 10.6 \\
\hline & General & 10.5 & & & \\
\hline
\end{tabular}

(Lewis, 1987; Stern, 1985; Watson, 1979, 1985), including emotional self-regulation and control (Kochanska, 1994; Kopp, 1989; Tronick, 1989), means-ends differentiation (Lewis \& Goldberg, 1969), self-efficacy and expectation of environmental control (Maccoby, 1992; Maccoby \& Martin, 1983), language development (Bornstein \& Tamis-LeMonda, 1997), and cognitive skills and academic achievement (Bornstein \& Tamis-LeMonda, 1989; Coates \& Lewis, 1984; Lewis, 1993). Inappropriate infant-caregiver interaction is also related to difficulties in the development of stress regulation competence (Schore, 2001), which may interfere with the reactivity of the hypothalamic-pituitary-adrenal axis and increase the child's vulnerability to stressful events (Gunnar, 1998). Furthermore, neuro-psycho-biological studies have pointed out the negative influence of poor early interaction on the growth and organization of the maturing brain, affecting both physiological and psychological development (Gunnar, 1998; Schore, 2001).

Both infant factors and the quality and pattern of mother-infant interaction are, therefore, relevant issues to consider in the study of (mal)adaptative pathways of infant development. The importance of this study relies on: (a) identifying and profiling groups of infants according to their behavioral and physiological characteristics considering simultaneously three relevant areas of functioning - neurobehavioral organization, social withdrawal behavior, and endocrine reactivity to acute stress; and (b) analyzing potential group differences in the quality of mother-infant interaction. In light of past findings we hypothesized that infants' profiles characterized by high social withdrawal behavior and low neurobehavioral organization are linked with worse mother-infant interactions (e.g., Nugent et al., 1993; Puura et al., 2007), while infants' profiles characterized by low endocrine reactivity are associated with optimal maternal behaviors in the interaction (Schore, 2001).

\section{Method}

\section{Sample}

The exclusion criteria for selecting the sample were: illiteracy and multiple gestations. The sample was composed of 97 mothers and infants. Ninety-six percent of mothers were younger than 35 years old, had more than 9 years of education $(97.0 \%)$, were married $(81.0 \%)$, and primiparous $(84.2 \%)$. The time of gestation ranged from 36 to 41 weeks and the majority of the infants were born after a normal (80.4\%) and full-term gestation (92.8\%). Normal vaginal delivery occurred in $34.2 \%$ of the cases. More than half of the infants were males $(53.1 \%)$, and generally there was no need for reanimation (94.6\%). At birth infants' height ranged from 45.90 $\mathrm{cm}$ to $54.00 \mathrm{~cm}(M=49.44 \mathrm{~cm}, S D=1.84)$, cephalic perimeter ranged from $31 \mathrm{~cm}$ to $37 \mathrm{~cm}(M=34.60 \mathrm{~cm}, S D=1.29)$, weight ranged from $2,450 \mathrm{~g}$ to $4,055 \mathrm{~g}(M=3,243 \mathrm{gr}, S D=424)$, the ponderal index ranged from 2.24 to $3.29(M=2.71, S D=0.23)$, and had an Apgar score ranging from 5 to $10(M=8.63, S D=0.91)$ in the first minute of life and ranging from 8 to $10(M=9.76, S D=0.53)$ in the fifth minute of life (see Table 1).

\section{Measures}

Neonatal behavior. The Neonatal Behavioral Assessment Scale (NBAS; Brazelton \& Nugent, 1995) assesses the newborn's competencies across different developmental areas-autonomic, motor, states, and social - and describes how these areas are integrated. The scale, composed of 28 behavioral and 18 reflex items, is suitable for examining newborns and infants up to 2 months old. The 28 items of the NBAS are scored on a 9-point scale. In this study, a reliable and certified researcher conducted and scored the NBAS. For the NBAS total score, behavioral and reflex items were recoded so that a better performance corresponded with a higher score and were then added. Cronbach's alphas of the scales ranged from .54 (autonomic stability) to .74 (range of state) (Costa et al., 2010), similar to those found in other studies (Moragas, Deu, Mussons, Boatella-Costa, \& Zurita, 2007).

Social withdrawal. The Alarm Distress Baby Scale (ADBB; Guedeney \& Fermanian, 2001) consists of eight items to assess prolonged reaction of social withdrawal in infants. The ADBB was created in order to help assess social withdrawal in children aged between 2 and 24 months, in the context of pediatrician routine physical examination or psychological assessment. The eight items, each rated from 0 to 4 (with low scores being optimal social behavior), are the following: facial expression; eye contact; general level of activity; self-stimulation gestures; vocalizations; briskness of response to stimulation; relationship to the observer; and attractiveness to the observer. The ADBB total score derives from the 
sum of the eight items. The higher the ADBB score, the more signs of social withdrawal are shown by the infant. In this study, the $\mathrm{ADBB}$ was scored based on the observation of the infant behavior toward others from the beginning of the consultation until the end. It was scored by two reliable independent coders. Interrater reliability was calculated using intraclass coefficient $(\mathrm{ICC}=.92)$. The Portuguese version of the scale has a reasonable internal consistency (Cronbach's $\alpha=.60$ ) (Figueiredo \& Costa, 2008), although a little lower than the original version (Guedeney \& Fermanian, 2001).

Endocrine reactivity to inoculation. Saliva samples were collected before $(5 \mathrm{~min})$ and after $(20 \mathrm{~min})$ routine inoculation (between 2 p.m. and 4 p.m.) at 8 to 12 weeks of life. All samples were collected at least $30 \mathrm{~min}$ after the last meal. Infants did not have any sign or symptom of illness at the time of inoculation. Mothers were instructed not to feed the infant before the end of saliva collection. Plastic tubes (Salivette; Sastedt, Numbrecht, Germany) containing a cotton roll, which was placed inside the infants' mouth for about 2-3 min, were utilized. On the day of testing, all specimens were taken to the laboratory (Ilgaia, Porto, Portugal) and centrifuged to remove mucus and stored in a freezer $\left(-20{ }^{\circ} \mathrm{C}\right)$. The saliva was assayed for cortisol concentration using Immulite 2000 cortisol, a chemiluminescent enzyme immunoassay (Sarstedt, Numbrecht, Germany). Cortisol units were expressed in $\mu \mathrm{g} / \mathrm{dl}$. Cortisol reactivity was determined by computing the difference between the posttest and pretest cortisol levels and referred to as $\delta$ cortisol.

Mother-infant interaction. The Global Rating Scales of Mother-Infant Interaction (GRS; Gunning, Fiori-Cowley, \& Murray, 1999; Murray, Fiori-Cowley, Hooper, \& Cooper, 1996) are a video-based assessment of the quality of mother-infant engagement that can be applied from 2 to 6 months postpartum. Mothers are instructed simply to play with their infants in any way they choose without the use of toys in a 5-min face-to-face play session. The scales globally assess the quality of: (a) mother's behavior, (b) infant's behavior, and (c) overall interaction. In this study a reliable researcher trained by the Winnicott Research Unit carried out the procedure and scored the mother-infant interactions (Gunning et al., 2004).

Mother's behavior was rated according to three subscales that describe the degree to which a mother's behavior is appropriately adjusted to her infant: (a) good-poor, computed through the average score of five items (warm/positive vs. cold/hostile, accepting vs. rejecting, responsive vs. unresponsive, nondemanding vs. demanding, sensitive vs. insensitive), with a sum score near 5 rated as "good" and a sum score near 1 rated as "poor"; (b) intrusiveremote, composed of four items (nonintrusive behavior vs. intrusive behavior, nonintrusive speech vs. intrusive speech, nonremote vs. remote, nonsilent vs. silent) using the following formula: ([intrusive behavior + intrusive speech $] / 2-[$ nonremote + silent $] / 2) / 2$ that gives a sum score running from -2 (intrusive) to +2 (remote), a sum score of 0 indicating that the person is neither intrusive nor remote; (c) depressive, computed through the average of four items (happy vs. sad, much energy vs. low energy, absorbed in the infant vs. self-absorbed, relaxed vs. tense), with the higher score indicating less depressive signs.

Infant behavior was rated according to two subscales, describing the infant's positive engagement in the interaction, and behavior: (a) good-poor, computed through the average of three items (attentive vs. avoidant, active communication vs. no active communication, positive vocalizations vs. no positive vocalizations), with a sum score near 5 rated as "good" and a sum score near 1 rated as "poor"; (b) inert-fretful, composed of five items (engaged with the environment vs. self-absorbed, lively vs. inert, attentive vs. avoidant, happy vs. distressed, nonfretful vs. fretful) using the formula ([engaged + lively + attentive] $/ 3-[$ happy + nonfretful] $/ 2$ ) $/ 2$, running from -2 (withdrawn) to +2 (fretful) with a sum score near 0 being optimal.

The overall interaction was rated using one subscale: (a) goodpoor, composed of the average score of five items (smooth/easy vs. difficult, fun vs. serious, satisfying vs. unsatisfying, much engagement vs. no engagement, excited engagement vs. quiet engagement), a sum score of 5 is "good interaction" and near 1 is "poor interaction."

Procedures. This research was conducted in two public primary health care centers. Mothers were contacted when attending to the routine inoculation of their 1-month-old infants. Seventy-nine percent of the mothers that were contacted agreed to participate, $16.5 \%$ declined to participate alleging lack of time and $4.5 \%$ were not interested in participating. The aims and the procedures of the study were explained, and an informed consent was signed. Research procedures were conducted in the primary health care centers when mothers attended to routine consultations for their infants. There were no dropouts during the study period. All evaluation procedures performed were videotaped.

A sociodemographic questionnaire was filled out on infants' medical data and at 8 weeks of life the Neonatal Behavioral Assessment Scale (NBAS; Brazelton \& Nugent, 1995) was performed. This examination was conducted by trained and reliable examiners midway between feeds in a quiet and semidarkened room with a temperature of $22-27^{\circ} \mathrm{C}$. The NBAS was scored immediately after performed. At this time infants' social withdrawal was scored using the Alarm Distress Baby Scale (ADBB; Guedeney \& Fermanian, 2001). Between 8 and 12 weeks of life a saliva sample was collected from the participants mouth before $(5 \mathrm{~min})$ and after $(20 \mathrm{~min})$ routine inoculation. Four weeks later, between 12 and 16 weeks of life the Global Rating Scales of Mother-Infant Interaction (GRS; Gunning et al., 1999; Murray et al., 1996) were performed, videotaped and rated by trained and reliable examiners.

\section{Results}

\section{Data reduction and statistical analyses}

For the classification of infants in groups according to their performance on NBAS, ADBB, and $\delta$ cortisol, a two-step procedure was performed. In the first step hierarchical cluster models were computed as an exploratory technique for indicating the $\mathrm{K}$ to be used in the second step: nonhierarchical cluster model. A hierarchical cluster analysis was performed using Ward's method with a Euclidean distance measure. The criterion used for the number of clusters to retain was the $R$-square and the solution of fewer clusters with higher total variance explained was chosen. The classification of participants in the clusters was then refined using the K-means nonhierarchical cluster analysis for three-cluster solution taking the Ward's results as starting values (Hair, Anderson, Tatham, \& Black, 1998). The statistical analysis of the $F$ ANOVA of the clusters was performed in order to identify the importance of each variable in the retained clusters. 
Each of the three variables-NBAS total score, ADBB total score and $\delta$ cortisol-considered in the cluster analysis were converted to standard scores ( $z$-scores). The standardization of the variables eliminates the bias introduced by the differences in the scales of the variables, thus allowing each of them to equally contribute to the formation of the clusters (Hair et al., 1998).

For purposes of validity, stepwise discriminant analysis based on Wilks' lambda was performed with the variables used in the cluster analysis (Blashfield \& Aldenderfer, 1988).

ANOVAs followed by the Bonferroni post hoc test (Field, 2005 ) were used to examine group differences on neurobehavioral organization, social withdrawal, and $\delta$ cortisol.

To analyze differences between groups on maternal and infant sociodemographic and medical data, chi-square tests were performed. Independent variables were: maternal age, education, marital status, parity, type of gestation, time of gestation, type of delivery, type of anesthesia, infant gender, reanimation at birth, weight, Apgar index at the first minute, and type of feeding.

Several multivariate analyses of variance (MANOVAs) followed by the univariate $F$ test and Bonferroni post hoc test (Field, 2005) were used to identify potential group differences on the quality of mother-infant interaction after the validation of the assumptions. The first MANOVA included maternal items as dependent variables; the second was performed taking infant items as dependent variables; the third taking the overall interaction items as dependent variables; and the fourth taking GRS subscales as dependent variables.

\section{Infants' behavioral and physiological profiles}

The three variables considered in the analysis were converted to standard scores: NBAS total score $(M=4.17 ; S D=.54)$, ADBB total score $(M=1.49 ; S D=1.92)$ and $\delta$ cortisol $(M=.30 ; S D=.37)$.

The hierarchical cluster analysis was performed using Ward's method with a Euclidean distance measure. Outliers were excluded using the criterion of distance from the mean greater than three times the value of the standard deviation. No Bravais-Pearson correlation coefficient was higher than .90 , indicating no problems of multicollinearity. A high increase of the agglomeration schedule from a two-cluster $(43.37 \%)$ to a three-cluster $(54.40 \%)$ solution suggests a three-cluster solution to be suitable. According to the $R$-squared criterion, three clusters were retained explaining $54.40 \%(R$-sq $=0.544)$ of the total variance.

In order to "fine-tune" the results and verify the stability of the clusters derived from the hierarchical cluster analysis, a nonhierarchical K-means cluster analysis for the three cluster solution taking Ward's results as starting values was performed. Outliers were excluded applying the criterion of more than 1.00 units from the nearest cluster center. All variables contributed significantly to the differentiation of clusters: NBAS, $F=39.825, p<.000$, ADBB, $F=62.697, p<.000$, and $\delta$ cortisol, $F=19.148, p<.000$.

The first cluster was labeled "withdrawn" profile and represents $17.0 \%$ of the sample. Infants in this cluster had a neurobehavioral organization below the sample mean, some signs of social withdrawal, and endocrine reactivity above the sample mean. The second cluster was labeled "extroverted" profile and represents $57.0 \%$ of the sample. Infants in this cluster had a neurobehavioral organization above the sample mean, and showed practically no symptoms of social withdrawal and an endocrine reactivity slightly above the sample mean. The third cluster was labeled

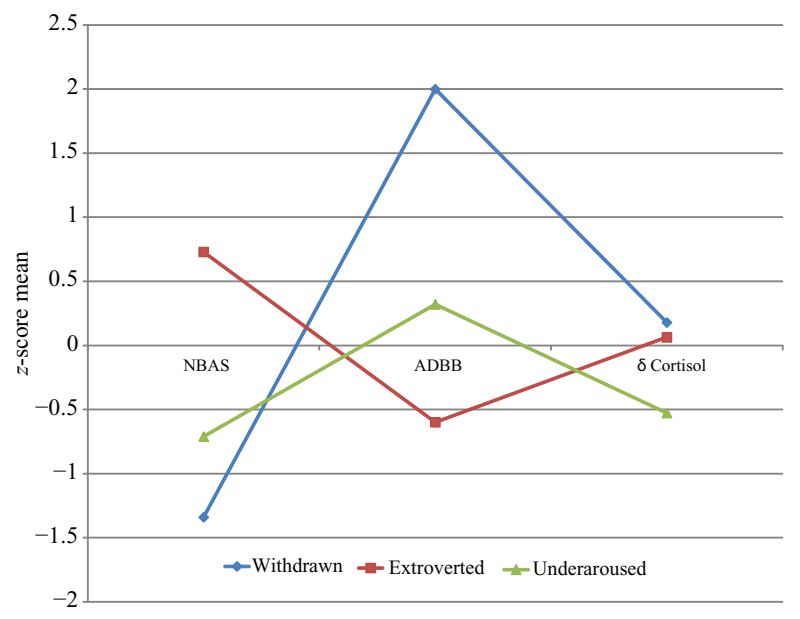

Figure I. Infants' behavioral and physiological profiles.

"underaroused" profile and represents $26.0 \%$ of the sample. Infants in this cluster showed a neurobehavioral organization similar to the sample mean, slight signs of social withdrawal, and endocrine reactivity below the sample mean. Figure 1 shows the cluster profiles.

Stepwise discriminant analysis based on Wilks' lambda was performed with the variables entered in the clusters to identify factors that significantly discriminate between the three clusters. The normality assumption was valid as the test of equality of group means for all variables is $<.05$. The homogeneity of variances/covariances for each cluster was tested with the M-Box test, $M=$ $35.701, F=2.626, p=.002$, and it was not valid. Nonetheless, discriminant functions are quite resistant to the violation of this assumption as long as the dimension of the lower group is higher than the number of variables under study and the mean of the groups is not proportional to their variances (Stevens, 1986). There were no problems of multicollinearity between variances since the Variance Inflation factor for all variables was $<5$ and the Tolerance $>.2$ (Field, 2005).

The stepwise discriminant analysis extracted two discriminant functions and retained ADBB, NBAS, and $\delta$ cortisol as significant variables. The two discriminant functions were significant. The first function was defined by $\mathrm{ADBB}$ and explained $89.6 \%$ of the variability between clusters with eigenvalues of 4.69. This function significantly discriminated between the three clusters, $\Lambda=0.114$, $\chi^{2}(6)=117.422, p=.000$. The second function retained was defined by NBAS and $\delta$ cortisol, and it explained $10.4 \%$ of the variability between clusters with eigenvalues of .55 , and it also discriminated between the clusters, $\Lambda=0.647, \chi^{2}(2)=23.492, p<.000$. The analysis showed that $94.8 \%$ of the cases were grouped correctly.

The ANOVA showed significant differences between groups on neurobehavioral organization, social withdrawal, and $\delta$ cortisol. The Bonferroni post hoc test showed that withdrawn infants had a worse performance on NBAS compared to extroverted and underaroused infants and that underaroused infants had worse performance on NBAS compared to extroverted infants. Furthermore, withdrawn infants showed more signs of social withdrawal compared to extroverted and underaroused infants, while underaroused infants showed more signs of social withdrawal compared to extroverted infants. Underaroused infants had significantly lower endocrine reactivity compared to withdrawn and extroverted infants. Table 2 shows the ANOVA results. 
Table 2. ANOVAs for analyzing differences on the three groups of infants

\begin{tabular}{|c|c|c|c|c|c|c|}
\hline & $\begin{array}{l}\text { Withdrawn (A) } \\
(n=16) \\
M(S D)\end{array}$ & $\begin{array}{l}\text { Extroverted }(B) \\
\quad(n=56) \\
M(S D)\end{array}$ & $\begin{array}{l}\text { Underaroused }(C) \\
\qquad(n=25) \\
M(S D)\end{array}$ & $F$ & $p$ & Post hoc \\
\hline NBAS & $3.47(.39)$ & $4.53(.24)$ & $3.73(.43)$ & 57.464 & .000 & $\begin{array}{l}\text { A vs. } B \\
A \text { vs. } C \\
B \text { vs. } C\end{array}$ \\
\hline $\mathrm{ADBB}^{\mathrm{a}}$ & $5.40(1.5 \mathrm{I})$ & $.44(.8 I)$ & $2.06(1.12)$ & 96.940 & .000 & $\begin{array}{l}\text { A vs. B } \\
\text { A vs. C } \\
\text { B vs. C }\end{array}$ \\
\hline$\delta$ cortisol & $.36(.33)$ & $.32(.29)$ & $.08(.16)$ & 4.510 & .015 & $\begin{array}{l}\text { A vs. C } \\
\text { B vs. C }\end{array}$ \\
\hline
\end{tabular}

Note. ${ }^{a}$ Higher score is worse performance.

Table 3. Univariate $F$ test for mothers' behavior in the interaction (GRS items)

\begin{tabular}{|c|c|c|c|c|c|c|}
\hline & $\begin{array}{l}\text { Withdrawn (A) } \\
(n=16) \\
\text { Mean (SD) }\end{array}$ & $\begin{array}{l}\text { Extroverted (B) } \\
\qquad(n=56) \\
\text { Mean (SD) }\end{array}$ & $\begin{array}{l}\text { Underaroused (C) } \\
\qquad(n=25) \\
\text { Mean (SD) }\end{array}$ & $F$ & $p$ & Post hoc \\
\hline Warm/positive & $4.14(.90)$ & $4.37(.56)$ & $4.73(.59)$ & 2.703 & .077 & \\
\hline Accepting & $4.29(.95)$ & $4.73(.52)$ & $4.73(.59)$ & 1.631 & .206 & \\
\hline Responsive & $3.86(1.07)$ & $4.30(.65)$ & $4.47(.52)$ & 1.908 & .159 & \\
\hline Nondemanding & $4.14(1.21)$ & $4.00(.98)$ & $4.07(.80)$ & .071 & .933 & \\
\hline Sensitive & $3.06(.90)$ & $4.03(.57)$ & $4.80(.51)$ & 3.784 & .030 & $\begin{array}{l}\text { A vs. } C \\
A \text { vs. } B \\
B \text { vs. } C\end{array}$ \\
\hline Nonintrusive behavior & $3.57(1.40)$ & $4.20(.92)$ & $4.07(.88)$ & 1.159 & .322 & \\
\hline Nonintrusive speech & $4.43(1.13)$ & $3.93(.98)$ & $4.20(.56)$ & 1.049 & .358 & \\
\hline Nonremote & $4.29(.95)$ & $4.33(.76)$ & $4.53(.64)$ & .422 & .658 & \\
\hline Nonsilent & $4.14(1.07)$ & $4.50(.78)$ & $4.80(.56)$ & 1.845 & .169 & \\
\hline Happy & $3.43(.79)$ & $4.00(.74)$ & $4.47(.64)$ & 5.179 & .009 & A vs. C \\
\hline Much energy & $3.89(.76)$ & $4.04(.62)$ & $4.78(.41)$ & 2.836 & .048 & $\begin{array}{l}A \text { vs. } C \\
B \text { vs. } C\end{array}$ \\
\hline Absorbed in the infant & $4.14(.90)$ & $4.30(.88)$ & $4.60(.63)$ & .973 & .385 & \\
\hline Relaxed & $4.00(1.00)$ & $4.50(.57)$ & 4.67 (.49) & 2.794 & .071 & \\
\hline
\end{tabular}

\section{Infants' behavioral and physiological profiles and mother-infant interaction}

Associations were tested between the three groups of infants ("withdrawn," "extroverted," and "underaroused") regarding maternal and infant sociodemographic and medical data, using chi-square tests. Maternal variables considered were age, education, marital status, parity, and type of pregnancy. Infant variables were time of gestation, type of delivery, type of anesthesia, gender, reanimation at birth, weight, Apgar index at the first minute, and type of feeding. No significant associations in maternal and infant sociodemographic and medical data were found between groups, so these variables were not controlled in further analyses.

In order to understand how infants with different behavioral and physiological profiles later interact with their mothers and vice versa, several multivariate analyses of variance (MANOVA) followed by univariate $F$ test and Bonferroni post hoc test were performed to analyze potential differences in groups regarding (a) mother's behavior, (b) infant's behavior, and (c) overall interaction. The validation of the assumption of homogeneity of variancescovariances using the M-Box test was guaranteed for maternal items, $M=190.695 ; F(91,2610)=1.247 ; p=.059$, infant items, $M=$ $31.879 ; F(28,2867)=.896 ; p=.623$, and interaction items, $M=$
$60.045 ; F(30,1131)=1.500 ; p=.051$. Nonetheless this assumption was not met for GRS subscales, $M=98.860 ; F(42,1078)=1.633$; $p=.007$. As there is no nonparametric test alternative to this test, we interpreted the results using the Pillai's trace, which is the most adequate under these circumstances.

\section{Mothers' behavior in the interaction}

The significance of infant behavioral and physiological profile on mothers' behavior in the interaction was evaluated with a MANOVA. The GRS maternal items were entered in the analysis, and were not statistically significant, Pillai's trace $=.561 ; F(2,96)=$ $1.140 ; p=.322$. Subsequent univariate analyses followed by the Bonferroni post hoc test indicated that mothers of withdrawn infants were less sensitive (CI95\% $[-1.25,-.30] ; p=.028)$, happy $(\mathrm{CI} 95 \%[-1.44,-.04] ; p=.035)$, and spent less energy (CI95\%[-1.64, -.26]; $p=.025)$ than mothers of underaroused infants and were less sensitive than mothers of extroverted (CI95\%[-1.28, -.40$] ; p=.042)$ infants. Mothers of underaroused infants were more sensitive $(\mathrm{CI} 95 \%[-1.87,-.21] ; p=.011)$ and spent more energy $(\mathrm{CI} 95 \%[-1.57,-.23] ; p=.042)$ in the interaction compared to mothers of extroverted infants (see Table 3 ). 
Table 4. Univariate $F$ test for infants' behavior in the interaction (GRS items)

\begin{tabular}{|c|c|c|c|c|c|c|}
\hline & $\begin{array}{l}\text { Withdrawn (A) } \\
\qquad(n=16) \\
\text { Mean (SD) }\end{array}$ & $\begin{array}{l}\text { Extroverted (B) } \\
(n=56) \\
\text { Mean (SD) }\end{array}$ & $\begin{array}{l}\text { Underaroused (C) } \\
\qquad(n=25) \\
\text { Mean (SD) }\end{array}$ & $F$ & $p$ & Post hoc \\
\hline Attentive & $3.43(1.13)$ & $4.50(0.68)$ & $3.84(1.10)$ & 4.549 & .015 & $\begin{array}{l}\text { A vs. B } \\
\text { B vs. } C\end{array}$ \\
\hline Active communication & $2.86(0.90)$ & $4.07(1.01)$ & $3.93(1.10)$ & 3.984 & .025 & A vs. $B$ \\
\hline Positive vocalizations & $2.14(0.69)$ & $3.87(1.07)$ & $3.67(1.11)$ & 7.778 & 然 & $\begin{array}{l}\text { A vs. } B \\
\text { A vs. } C\end{array}$ \\
\hline Engaged with environment & 3. $86(1.21)$ & $4.83(0.59)$ & $4.00(0.74)$ & 5.000 & .011 & $\begin{array}{l}\text { A vs. B } \\
\text { B vs. C }\end{array}$ \\
\hline Lively & $3.86(0.38)$ & $4.50(0.78)$ & $4.40(0.74)$ & 2.219 & .120 & \\
\hline Happy & $2.86(0.38)$ & $3.77(0.94)$ & $3.33(0.90)$ & 3.538 & .037 & A vs. $B$ \\
\hline Nonfretful & $4.00(1.00)$ & $4.30(0.84)$ & $4.13(0.92)$ & .412 & .665 & \\
\hline
\end{tabular}

Table 5. Univariate $F$ test for the overall interaction (GRS items)

\begin{tabular}{|c|c|c|c|c|c|c|}
\hline & $\begin{array}{l}\text { Withdrawn (A) } \\
(n=16) \\
\text { Mean }(S D)\end{array}$ & $\begin{array}{c}\text { Extroverted (B) } \\
(n=56) \\
\text { Mean }(S D)\end{array}$ & $\begin{array}{l}\text { Underaroused }(C) \\
\qquad(n=25) \\
\text { Mean (SD) }\end{array}$ & $F$ & $p$ & Post hoc \\
\hline Smooth/easy & $3.14(1.07)$ & $4.23(0.73)$ & $4.07(1.03)$ & 4.854 & .012 & $\begin{array}{l}\text { A vs. } B \\
\text { A vs. C }\end{array}$ \\
\hline Fun & $2.7 \mathrm{I}(0.95)$ & $3.77(0.94)$ & $2.97(0.99)$ & 3.518 & .037 & $\begin{array}{l}\text { A vs. } B \\
\text { B vs. } C\end{array}$ \\
\hline Satisfying & $2.86(0.90)$ & $3.90(0.88)$ & $3.53(1.13)$ & 3.505 & .038 & A vs. $B$ \\
\hline Much engagement & $3.43(1.27)$ & $4.70(0.53)$ & $4.40(1.06)$ & 6.715 & .003 & $\begin{array}{l}\text { A vs. } B \\
\text { A vs. } C\end{array}$ \\
\hline Excited engagement & $2.43(0.79)$ & $3.77(0.82)$ & $3.33(1.35)$ & 5.318 & .008 & A vs. $B$ \\
\hline
\end{tabular}

\section{Infants' behavior in the interaction}

The significance of infants' behavioral and physiological profile on infants' behavior in the interaction (GRS infant items) was evaluated with a MANOVA. The GRS infant items were entered in the analysis, and were statistically significant, Roy's largest root $=.406 ; F(2,96)=2.552 ; p=.027$. Subsequent univariate analyses followed by the Bonferroni post hoc test (see Table 4) indicated that compared to extroverted infants, withdrawn infants were less attentive (CI95\%[-2.10, -.14]; $p=.021)$, showed less active communication (CI95\%[-2.30, -.12]; $p=.026)$, less positive vocalizations $(\mathrm{CI} 95 \%[-2.83,-.61] ; p=.001)$, less engagement with the environment (CI95\% $[-1.76,-.19] ; p=.011)$, and were less happy (CI95\% $[-1.84,-.02] ; p=.056)$. Compared to underaroused infants, withdrawn infants had less positive vocalizations (CI95\%[-2.73, -.31$] ; p=.010)$. Compared to extroverted infants, underaroused infants were less attentive (CI95\% $[-1.95$, $-.34] ; p=.045)$ and less engaged with the environment (CI95\%[-1.60,-.20]; $p=.030)$.

\section{Overall interaction}

The significance of the clusters on overall interaction (GRS items) was evaluated with a MANOVA. The GRS overall interaction items were entered in the analysis, and were statistically significant, Roy's largest root $=.358 ; F(2,96)=3.250 ; p=.013$. Subsequent univariate analyses followed by the Bonferroni post hoc test indicated a significant effect of all the items of the overall interaction (see Table 5). Compared to overall interaction of extroverted infants, the overall interaction of withdrawn infants was more difficult (CI95\%[-2.10, -.17]; $p=.017)$, serious (CI95\%[-2.06, $-.04] ; p=.039)$, unsatisfying (CI95\%[-2.06, -.02$] ; p=.044)$, showed less engagement (CI95\%[-2.15, -.39]; $p=.003)$, and less excited engagement (CI95\% $[-2.39,-.28] ; p=.009)$. Compared to the overall interaction of underaroused infants, the overall interaction of withdrawn infants was more difficult (CI95\%[-2.13, -.12]; $p=.025)$ and with less engagement (CI95\%[-1.98, -.01$] ; p=$ .046). Compared to extroverted infants, underaroused infants had less fun in the interaction (CI95\% $[-2.16,-.31] ; p=.042)$.

A multivariate analysis of variance (MANOVA) for identifying potential group differences on the GRS subscales was performed. The GRS subscales were entered in the analysis, and were marginally significant, (Pillai's trace $=.390 ; F(2,96)=$ $1.817 ; p=.057$. Subsequent univariate analyses followed by the Bonferroni post hoc test indicated a significant effect of mother depressive subscale, infant attentiveness/communication subscale, and overall interaction subscale (see Table 6). Compared to extroverted infants, withdrawn infants were less attentive/communicative (CI95\%[-2.22, -.45]; $p=.002)$ and the overall interaction was worse $(\mathrm{CI} 95 \%[-2.01,-.30] ; p=$ $.005)$. Compared to underaroused infants, withdrawn infants' mothers had more depressed behaviors in the interaction (CI95\%[-1.25, -.09]; $p=.020)$, were less attentive/communicative $(\mathrm{CI} 95 \%[-2.05,-.11] ; p=.025)$, and the overall interaction was worse $(\mathrm{CI} 95 \%[-1.82,-.05] ; p=.066)$. Extroverted and underaroused infants differ in that extroverted were more attentive/communicative than underaroused infants (CI95\%[-1.80, -.20]; $p=.032)$. 
Table 6. Univariate $F$ test for GRS subscales

\begin{tabular}{|c|c|c|c|c|c|c|c|}
\hline & & $\begin{array}{c}\text { Withdrawn (A) } \\
\qquad(n=16) \\
\text { Mean (SD) }\end{array}$ & $\begin{array}{l}\text { Extroverted (B) } \\
\quad(n=56) \\
\text { Mean }(S D)\end{array}$ & $\begin{array}{l}\text { Underaroused (C) } \\
\qquad(n=25) \\
\text { Mean (SD) }\end{array}$ & $F$ & $p$ & Post hoc \\
\hline \multirow[t]{3}{*}{ Mother } & Good vs. poor & $4.06(.75)$ & $4.37(.42)$ & $4.52(.48)$ & 2.141 & .128 & \\
\hline & Intrusive vs. remote & $-.11(.64)$ & $-.17(.48)$ & $-.27(.33)$ & .327 & .722 & \\
\hline & Depressive* & $3.96(.57)$ & $4.30(.54)$ & $4.63(.38)$ & 4.608 & .015 & A vs. $C$ \\
\hline \multirow[t]{2}{*}{ Infant } & $\begin{array}{l}\text { Attentive/ } \\
\text { communicative }\end{array}$ & $2.8 \mathrm{I}(.8 \mathrm{I})$ & $4.14(.78)$ & $3.40(.95)$ & 7.231 & .002 & $\begin{array}{l}\text { A vs. } B \\
\text { A vs. C }\end{array}$ \\
\hline & Inert vs. fretful & $.14(.53)$ & $.29(.39)$ & $.31(.46)$ & .400 & .673 & B vs. C \\
\hline Interaction & Overall interaction & $2.91(.87)$ & $4.07(.66)$ & $3.80(1.02)$ & 5.886 & .005 & $\begin{array}{l}\text { A vs. B } \\
\text { A vs. C }\end{array}$ \\
\hline
\end{tabular}

Note. *Higher score indicates less depressive signs.

\section{Discussion}

This study was conducted with the aim of (a) identifying and profiling groups of infants according to behavioral and physiological characteristics, and (b) analyzing potential group differences in the quality of mother-infant interaction.

In the study of neonatal behavioral and physiological characteristics, three profiles were identified: (a) "withdrawn," (b) "extroverted," and (c) "underaroused." Thomas, Chess, and Birch (1968) argued that as early as the age of 2 or 3 months infants display a discernible behavioral profile. The authors derived three patterns of temperament based on the constellation of the nine characteristics: "difficult," "easy," and "slow to warm up." The "difficult" children have problems in adapting to different situations, withdraw from stimulus, and express more negative mood similarly to the "withdrawn" infants of this study. The "easy" children resemble the "extroverted" infants of this study in their adaptability and approach features. The "slow to warm up" are slow to adapt and show low intensity of reactions, which resembles the "underaroused" infants of this study.

Differences between groups in terms of maternal and infant sociodemographic and medical data were not found, probably because this study was performed with a low social and medical risk sample.

Differences between groups were noted regarding the quality of mother-infant interaction which is commensurate with the transactional perspective (Tronick, 2007). In general, the quality of mother-infant interaction was scored lower in the group of withdrawn infants compared to extroverted and underaroused infants and it was slightly lower in the group of underaroused compared to extroverted infants. Considering the fact that this study was conducted after 8 weeks of life, at the date of this study there was already a history of 8 weeks of mother-infant interactions. Thus, this may be the result of the following processes: (a) the influence of significant relations on the infants' behavioral and physiological characteristics, and (b) the influence of behavioral individual differences early in life on the development of significant relations (van den Boom \& Hoeksma, 1994).

The fact that underaroused infants were those with lower endocrine response to acute stress and their mothers were the most competent in the interaction - more sensitive, happy, and with more energy to interact - might be indicative of the critical role of the caregiver's behavior on the modulation of the infant's regulation of biological responses to stressors (Gunnar \& Quevedo, 2008). Greater endocrine reactivity and recovery in infants exposed to stressful and nonstressful situations as well as in everyday activities has been associated with lower maternal sensitivity and responsivity (e.g., Albers et al., 2008; Gunnar, Larson, Hertsgaard, Harris, \& Brodersen, 1992; Haley \& Stansbury, 2003; Spangler et al., 1994). So, it seems that competent maternal behavior is important in order to provide the infant with external regulation for his/her physiological states (Albers et al., 2008), playing an important role in the regulation of the infants' hypothalamic-pituitary-adrenal (HPA) axis response to stressful situations (Liu et al., 1997).

Another important result was the fact that although both extroverted infants and withdrawn infants have identical endocrine response to acute stress, they are quite different in their behavioral characteristics. In fact, extroverted infants were the ones with better performance on neurobehavioral organization and social withdrawal. Additionally, they have expressed more positive behaviors in the interaction and the overall quality of mother-infant interaction was better. This finding supports the idea that behavioral features early in life influence the development of significant relations, and is consistent with previous findings of Nugent et al. (1993) and Murray, Stanley, Hooper, King, and Fiori-Cowley (1996) that noted that a better neonatal neurobehavior was associated with better mother-infant interactions. Considering the fact that social experiences have an impact on the stress-related systems (Ouellet-Morin et al., 2011), and that early rearing environment has an impact on stress sensitivity (Dougherty, Klein, Rose, \& Laptook, 2011), we may speculate that extroverted infants are in a more favorable condition to experience positive changes on endocrine response to stress throughout their development.

With regard to the comparison of withdrawn infants with the other two groups of infants, the results of this study were consistent with the results of Puura et al. (2007). These authors reported that withdrawn infants had a poor performance during the interaction with their mothers compared to nonwithdrawn infants. Additionally, mothers of socially withdrawn infants demonstrated less optimal behaviors in the interaction with their infants when compared to mothers of nonwithdrawn infants. A possible explanation is that, since these mothers expressed significantly more depressive behaviors in the interaction, it is possible that they were experiencing psychological difficulties that influence both their behaviors in the interaction and the quality of the overall interaction (e.g., Boyd, Zayas, \& McKee, 2006; Tronick \& Weinberg, 1997). Nonetheless, 
whatever might be the explanation for the mechanisms beneath this pattern of behaviors, this group of infants may be considered a risk group for developmental difficulties, because the impairment of the quality of interaction has been related to later infant difficulties (Evans \& Porter, 2009).

The identification of infants with different behavioral and physiological profiles may contribute to the understanding of developmental trajectories that could lead to (mal)adaptative development. This study highlights the fact that withdrawn infants may be at risk for developmental difficulties due to both infant and mother difficulties in the interaction. The lack of connectedness that characterizes both mothers' and withdrawn infants' behavior in the interaction may be the result of mothers missing or misinterpreting their infants' cues and so they are unresponsive/insensitive to those cues, thus ignoring, rejecting, or failing to comfort the infant. The quality of infant interaction with the primary caregiver is a relevant issue because within this relationship the infant develops a sense of what is expected of him/her and of what is possible in the relationship with others. The infant will also develop competencies for social initiation, reciprocity, synchrony, and cooperation. Furthermore, the capacity for increased emotional regulation and self-control develops throughout repeated positive social experiences (Zero to Three, 2005).

Previous studies pointed out the importance of specific psychological aspects of infants on the quality of mother-infant interaction. The major contribution of this study relies on considering the interplay of both infant behavioral and physiological features and considering the mutual influence of infants and mothers on the quality of mother-infant interaction. Further research is needed to study the developmental pathways of different groups of infants, namely the mediator effect of the quality of mother-infant interaction on the association between infants' behavioral and physiological profile and child development. Future research should also address the different behavioral and physiological profiles as potential precursors of psychological problems such as depression, anxiety, attention deficit, hyperactivity disorder, or autism, in order to understand the developmental pathways of these disorders.

\section{Acknowledgments}

We would like to thank the participants in this study and the Primary Health Center of Espinho and Santa Maria da Feira. We gratefully acknowledge the work of Catarina Magalhães, and Filomena Louro of the Scientific Editing Programme of University of Minho, in revising this article.

\section{Funding}

This study was financed by the Portuguese Foundation for Science and Technology (Grant with the reference SFRH/BD/18249/2004). Ministry of Science, Technology and Higher Education in the scope of POCI 2010. Advanced training for science-measure IV.3. Reimbursed by the European Social Fund and by national funds of MCTES.

\section{References}

Albers, E. M., Riksen-Walraven, J. M., Sweep, F., \& de Weerth, C. (2008). Maternal behavior predicts infant cortisol recovery from a mild everyday stressor. Journal of Child Psychology and Psychiatry, 49(1), 97-103.

Ashman, S. B., Dawson, G., Panagiotides, H., Yamada, E., \& Wilkinson, C. W. (2002). Stress hormone levels of children of depressed mothers. Development and Psychopathology, 14, 333-349.
Azar, R., Paquette, D., Zoccolillo, M., Baltzer, F., \& Tremblay, R. E. (2007). The association of major depression, conduct disorder, and maternal overcontrol with a failure to show a cortisol buffered response in 4-month-old infants of teenage mothers. Biological Psychiatry, 62(6), 573-579.

Bell, R. (1968). A reinterpretation of the direction of the effects in the studies of socialization. Psychological Review, 75, 81-95.

Blashfield, R., \& Aldenderfer, M. (1988). The methods and problems of cluster analysis. In J. R. Nesselroade \& R. B. Cattell (Eds.), Handbook of multivariate experimental psychology (2nd ed.). New York, NY: Plenum Press.

Bornstein, M. H., \& Tamis-LeMonda, C. S. (1989). Maternal responsiveness and cognitive development in children. In M. H. Bornstein (Ed.), New directions for child development: No. 43. Maternal responsiveness: Characteristics and consequences (pp. 49-61). San Francisco, CA: Jossey-Bass.

Bornstein, M. H., \& Tamis-LeMonda, C. S. (1997). Maternal responsiveness and infant mental abilities: Specific predictive relations. Infant Behavior and Development, 20, 283-296.

Boyd, R. C., Zayas, L. H., \& McKee, M. D. (2006). Mother-infant interaction, life events and prenatal and postpartum depressive symptoms among urban minority women in primary care. Maternal and Child Health Journal, 10(2), 139-148.

Brazelton, T. B., \& Nugent, J. K. (1995). Neonatal Behavioral Assessment Scale (3rd ed.). London, UK: Mac Keith Press.

Cernic, L. S., \& Pennington, B. F. (1987). Developmental psychology and neuroscience: An introduction. Child Development, 58, 533-538.

Coates, D. L., \& Lewis, M. (1984). Early mother-infant interaction and infant cognitive status as predictors of school performance and cognitive behavior in six-year-olds. Child Development, 55(4), 1219-1230.

Cohn, J. F., \& Tronick, E. Z. (1983). Three-month-old infants' reaction to simulated maternal depression. Child Development, 54, 185-193.

Costa, R., Figueiredo, B., Tendais, I., Conde, A., Pacheco, A., \& Teixeira, C. (2010). Brazelton Neonatal Behavioral Assessment Scale: A psychometric study in a Portuguese sample. Infant Behavior and Development, 33(4), 510-517.

Crockenberg, S. B., \& Smith, P. (2002). Antecedents of mother-infant interaction and infant irritability in the first 3 months of life. Infant Behavior \& Development, 25(1), 2-15.

Dawson, G., Frey, K., Panagiotides, H., Yamada, E., Hessl, D., \& Osterling, J. (1999) Infants of depressed mothers exhibit atypical frontal electrical brain activity during interactions with mother and with a familiar, nondepressed adult. Child Development, 70, 1018-1066.

Dougherty, L. R., Klein, D. N., Rose, S., \& Laptook, R. S. (2011). Hypothalamic-pituitary-adrenal axis reactivity in the preschoolage offspring of depressed parents: Moderation by early parenting. Psychological Science, 22(5), 650-658.

Evans, C. A., \& Porter, C. L. (2009). The emergence of mother-infant coregulation during the first year: Links to infants' developmental status and attachment. Infant Behavior \& Development, 32(2), 147-158.

Field, A. (2005). Discovering statistics using SPSS. London, UK: SAGE Publications.

Field, T., Diego, M. A., Hernandez-Reif, M., \& Ascencio, A. (2009). Prenatal disthymia versus major depression effects on early mother-infant interactions: A brief report. Infant Behavior \& Development, 32, 129-131.

Figueiredo, B., \& Costa, R. (2008). Estudo de validação da versão portuguesa da Alarm Distress Baby Scale (ADBB) [Validation study of the Alarm Distress Baby Scale (ADBB)]. Acta Pediatrica Portuguesa, 39(5), 183-189. 
Granger, D. A., Weisz, J. R., \& Kauneckis, D. (1994). Neuroendocrine reactivity, internalizing behavior problems, and control-related cognitions in clinic-referred children and adolescents. Journal of Abnormal Psychology, 103(2), 267-276.

Guedeney, A. (1997). From early withdrawal reaction to infant depression: A baby alone does exist. Infant Mental Health Journal, 18(4), 339-349.

Guedeney, A. (2007). Withdrawal behavior and depression in infancy. Infant Mental Health Journal, 28(4), 393-408.

Guedeney, A., \& Fermanian, J. (2001). A validity and reliability study of assessment and screening for sustained withdrawal reaction in infancy: The Alarm Distress Baby Scale. Infant Mental Health Journal, 22(5), 559-575.

Guedeney, A., Foucault, C., Bougen, E., Larroque, B., \& Mentré, F. (2008). Screening for risk factors of relational withdrawal behavior in infants aged 14-18 months. European Psychiatry, 23, 150-155.

Gunnar, M. R. (1998). Quality of early care and buffering of neuroendocrine stress reactions: Potential effects on the developing human brain. Preventive Medicine, 27, 208-211.

Gunnar, M. R., Larson, M. C., Hertsgaard, M., Harris, M., \& Brodersen, L. (1992). The stressfulness of separation among nine-month-old infants: Effects of social context variables and infant temperament. Child Development, 63, 290-303.

Gunnar, M. R., \& Quevedo, K. M., (2008). Early care experiences and HPA axis regulation in children: A mechanism for later trauma vulnerability. Progress in Brain Research, 167, 137-149.

Gunning, M., Conroy, V., Valoriani, V., Figueiredo, B., Kammerer, M., Nuzik, M., ... TCS-PND Group. (2004). Measurement of mother-infant interactions and the home environment in a European setting: Preliminary results from a cross-cultural study [Supplemental material]. British Journal of Psychiatry, 184(46), s38-s44.

Gunning, M., Fiori-Cowley, A., \& Murray, L. (1999). The global ratings of mother-infant interaction-Scoring manual (2nd ed.). Reading, UK: Winnicott Research Unit, University of Reading.

Hair, J. F., Anderson, R. E., Tatham, R. L., \& Black, W. C. (1998). Multivariate data analysis (5th ed.). Englewood Cliffs, NJ: Prentice-Hall.

Haley, D. W., \& Stansbury, K. (2003). Infant stress and parental responsiveness: Regulation of physiology and behavior during the still-face and reunion. Child Development, 74, 1534-1546.

Hornstein, C., Trautmann-Villalba, P., Hohm, E., Rave, E., WortmannFleisher, S., \& Schwarz, M. (2006). Maternal bond and motherchild interaction in severe postpartum psychiatric disorders: Is there a link? Archives of Women's Mental Health, 9, 279-284.

Horowitz, F. D., \& Linn, P. L. (1984). Use of the NBAS in research. In T. B. Brazelton (Ed.), Neonatal Behavioral Assessment Scale (2nd ed., pp. 97-104). London, UK: Spastics International Medical Publications.

Kaplan, L. A., Evans, L., \& Monk, C. (2008). Effects of mothers' prenatal psychiatric status and postnatal caregiving on infant biobehavioral regulation: Can prenatal programming be modified? Early Human Development, 84(4), 249-256.

Kerbel, B., Mertesacker, B., \& Pauli-Pott, U. (2004). Mother-infant interaction and adrenocortical reactivity in infancy. Psychotherapie Psychosomatik Medizinische Psychologie, 54(6), 243-249.

Kochanska, G. (1994). Beyond cognition: Expanding the search for the early roots of internalization and conscience. Developmental Psychology, 30(1), 20-22.

Kopp, C. B. (1989). Regulation of distress and negative emotions: A developmental view. Developmental Psychology, 25, 343-354.
Lewis, M. (1987). Social development in infancy and early childhood. In J. D. Osofsky (Ed.), Handbook of infant development (pp. 419-493). New York, NY: John Wiley \& Sons.

Lewis, M. (1993). The development of anger and rage. In R. A. Glick \& S. P. Roose (Eds.), Rage, power, and aggression: The role of affect in motivation, development, and adaptation (pp. 148-168). New Haven, CT: Yale University Press.

Lewis, M., \& Goldberg, S. (1969). Perceptual-cognitive development in infancy: A generalized expectancy model as a function of the mother-infant interaction. Merrill-Palmer Quarterly, 15, 81-100.

Liu, D., Diorio, J., Tannenbaum, B., Caldji, C., Francis, D., Freedman, A., ... Meaney, M. J. (1997). Maternal care, hippocampal glucocorticoid receptors, and hypothalamic-pituitary-adrenal responses to stress. Science, 277(5332), 1659-1662.

Locke, S., Ader, R., Besedovsky, H., Hull, N., Solomon, G., \& Strom, T. (1985). Foundations of psychoneuroimmunology. New York, NY: Aldine.

Lopez-Duran, N. L., Kovacs, M., \& George, C. J. (2009). Hypothalamic-pituitary-adrenal axis dysregulation in depressed children and adolescents: A meta-analysis. Psychoneuroendocrinology, 34, 1272-1283.

Lundqvist-Persson, C. (2001). Correlation between level of selfregulation in the newborn infant and developmental status at two years of age. Acta Paediatrica, 90, 345-350.

Maccoby, E. E. (1992). The role of parents in the socialization of children: An historical overview. Developmental Psychology, 28, 1006-1017.

Maccoby, E. E., \& Martin, J. (1983). Socialization in the context of the family: Parent-child interaction. In P. H. Mussen (Series Ed.) \& E. M. Hetherington (Vol. Ed.), Handbook of child psychology. Vol. 4: Socialization, personality, and social development (pp. 1-101). New York, NY: John Wiley and Sons.

Milne, L., Greenway, P., Guedeney, A., \& Larroque, B. (2009). Long term developmental impact of social withdrawal in infants. Infant Behavior \& Development, 32(2), 159-166.

Moragas, C. C., Deu, A. F., Mussons, F. B., Boatella-Costa, E., \& Zurita, M. L. (2007). Evaluación psicométrica de la Escala de Brazelton en una muestra de recién nacidos españoles. Psicothema, 19(1), 140-149.

Murray, L., \& Cooper, P. (1997). The role of infant and maternal factors in postpartum depression, mother-infant interactions and infant outcomes. In L. Murray \& P. Cooper (Eds.), Postpartum depression and child development (pp. 111-135). New York, NY: Guilford Press.

Murray, L., Fiori-Cowley, A., Hooper, R., \& Cooper, P. J. (1996). The impact of postnatal depression and associated adversity on early mother-infant interactions and later infant outcome. Child Development, 67, $2512-2626$.

Murray, L., Stanley, C., Hooper, R., King, F., \& Fiori-Cowley, A. (1996). The role of infant factors in postnatal depression and mother-infant interaction. Developmental Medicine and Child Neurology, 38(2), 109-119.

Nugent, J. K., Greene, S., Wieczorek-Deering, D., Mazor, K., Hendler, J., \& Bombardier, C. (1993). The cultural context of mother-infant play in the newborn period. In K. MacDonald (Ed.), Parent-child play: Description and implications (pp. 367-389). Albany: State University of New York Press.

Ouellet-Morin, I., Danese, A., Bowes, L., Shakoor, S., Ambler, A., Pariante, C. M., ... Arseneault, L. (2011). A discordant monozygotic twin design shows blunted cortisol reactivity among bullied 
children. Journal of the American Academy of Child and Adolescent Psychiatry, 50(6), 574-582.

Pérez-Edgar, K., Schmidt, L., Henderson, H., Schulkin, J., \& Fox, N. (2008). Salivary cortisol levels and infant temperament shape developmental trajectories in boys at risk for behavioral maladjustment. Psychoneuroendocrinology, 33, 916-925.

Puura, K., Guedeney, A., Mantymaa, M., \& Tamminen, T. (2007). Detecting infants in need: Are complicated measures really necessary? Infant Mental Health Journal, 28(4), 409-421.

Schore, A. N. (2001). Effects of a secure attachment relationship on right brain development, affect regulation, and infant mental health. Infant Mental Health Journal, 22, 7-66.

Slentz, K. L., \& Krogh, S. L. (2001). Early childhood development and its variations. Mahwah, NJ: Lawrence Erlbaum Associates.

Sostek, A. M., \& Anders, T. F. (1977). Relationship among the Brazelton neonatal scale, Bayley infant scales, and early temperament. Child Development, 48, 320-323.

Spangler, G., Schieche, M., Ilg, U., Maier, U., \& Ackerman, C. (1994). Maternal sensitivity as an external organizer for biobehavioral regulation in infancy. Developmental Psychobiology, 27, 425-437.

Stern, D. N. (1985). The interpersonal world of the infant. New York, NY: Basic Books.

Stevens, J. (1986). Applied multivariate statistics for the social sciences (2nd ed.). Hillsdale, NJ: Lawrence Erlbaum Associates.
Thomas, A., Chess, S., \& Birch, H. G. (1968). Temperament and behavior disorders in children. New York: New York University Press.

Tronick, E. (1989). Emotions and emotional communication in infants. American Psychologist, 44(2), 112-119.

Tronick, E. (2007). The neurobehavioral and social-emotional development of infants and children. New York: W. W. Norton.

Tronick, E., \& Weinberg, M. K. (1997). Depressed mothers and infants: Failure to form dyadic states of consciousness. In L. Murray \& P. Cooper (Eds.), Postpartum depression and child development (pp. 54-84). New York, NY: Guilford Press.

Van den Boom, D.C., \& Hoeksma, J. B. (1994). The effects of infant irritability on mother-infant interaction: A growth-curve analysis. Developmental Psychology, 30, 581-590.

Watson, J. S. (1979). Perception of contingency as a determinant of social responsiveness. In E. B. Thoman (Ed.), Origins of the infant's social responsiveness (pp. 33-64). Hillsdale, NJ: Lawrence Erlbaum Associates.

Watson, J. S. (1985). Contingency perception in early social development. In T. M. Field \& N. A. Fox (Eds.), Social perception in infants (pp. 157-176). Norwood, NJ: Ablex.

Zero to Three. (2005). Diagnostic classification of mental health and developmental disorders of infancy and early childhood: Revised edition (DC:0-3R). Washington, DC: Zero to Three Press. 